\title{
The Effectiveness of Total Worker Health Interventions: A Systematic Review for a National Institutes of Health Pathways to Prevention Workshop
}

\author{
Cynthia Feltner, MD, MPH; Kristina Peterson, PhD; Rachel Palmieri Weber, PhD; Laurie Cluff, PhD; \\ Emmanuel Coker-Schwimmer, MPH; Meera Viswanathan, PhD; and Kathleen N. Lohr, PhD
}

Background: The Total Worker Health (TWH) program of the National Institute for Occupational Safety and Health aims to advance worker well-being by integrating injury and illness prevention efforts with work-related safety and health hazard efforts.

Purpose: To evaluate evidence on the benefits and harms of integrated TWH interventions.

Data Sources: MEDLINE, Cochrane Library, and PsycINFO (January 1990 through September 2015); clinical trial registries; and reference lists.

Study Selection: English-language studies that enrolled employed adults and compared integrated interventions with usual work practice, no intervention, or another intervention.

Data Extraction: Dual abstraction and risk-of-bias (ROB) assessment.

Data Synthesis: Ten of the 15 included studies had high ROB, primarily because of selection and attrition bias. Findings graded as having low strength of evidence (SOE) supported the effectiveness of TWH interventions for improving smoking cessation, as measured by self-reported 7-day abstinence over 22 to 26 weeks ( 2 randomized, controlled trials [RCTs]; $n=737$ ), and increasing consumption of fruits and vegetables over 26 to 104 weeks ( $3 \mathrm{RCT} s ; n=6056$ ); results apply to populations of bluecollar manufacturing and construction workers. Findings graded as having low SOE supported the effectiveness of TWH interventions for reducing sedentary work behavior in office workers over 16 to 52 weeks ( 2 RCTs; $n=262$ ). Evidence was insufficient or lacking for other outcomes of interest, such as rates of work injuries, quality of life, and harms.

Limitation: Small, diverse body of evidence with many methodological limitations; possible publication bias.

Conclusion: Integrated TWH interventions might improve health behaviors (for example, reduce tobacco use and sedentary behavior and improve diet) of workers, but effects of these interventions on injuries and overall quality of life are not known.

Primary Funding Source: Agency for Healthcare Research and Quality.

Ann Intern Med. 2016;165:262-269. doi:10.7326/M16-0626 www.annals.org For author affiliations, see end of text.

This article was published at www.annals.org on 31 May 2016
T raditionally, occupational safety and health (OSH) and health promotion (HP) efforts have functioned independently in workplaces (1). Occupational safety and health interventions focus on preventing workrelated injuries and illnesses, which can lead to morbidity, mortality, and considerable financial and social costs (2-4). Health promotion interventions, often called wellness programs, promote overall health and well-being. They often address modifiable behavior risk factors, such as smoking, physical activity, and diet, which are leading causes of morbidity and mortality in the United States (5).

In the past decade, interest in integrating OSH and HP interventions has grown substantially $(1,6)$. This is partly explained by the emergence of evidence supporting the idea that workplace factors contribute to adverse health outcomes traditionally considered to be unrelated to work (such as cardiovascular disease and depression) (7).

\section{See also:}

Related article . . . . . . . . . . . . . . . . . . . . 279

Editorial comments

294,296

Web-Only

Supplement
The National Institute for Occupational Safety and Health (NIOSH), a part of the Centers for Disease Control and Prevention, focused attention on integrated approaches to worker health and safety in 2011 by creating the Total Worker Health (TWH) program. "Total Worker Health" is currently defined as "policies, programs, and practices that integrate protection from work-related safety and health hazards with promotion of injury and illness prevention efforts to advance worker well-being" (8). Earlier descriptions of TWH highlighted the strategic integration of $\mathrm{OSH}$ and traditional worksite HP programs (9); NIOSH's current definition is broader and emphasizes work-related factors (such as wages, workload, and stress levels) as important factors in determining worker well-being (10).

"TWH," a trademarked term, was not commonly used in past studies of integrated interventions. For this review, we use the term "TWH interventions" to refer to integrated interventions that are consistent with NIOSH's TWH initiative even if they differ in intent, complexity, and approach to integration. For example, an "integrated" intervention may involve strategic coordination between staff responsible for $\mathrm{OSH}$ and HP decision making to develop comprehensive, multicomponent programs to improve worker health and safety. Integrated interventions may also involve singlecomponent interventions (or policies) that simultane- 
ously address $\mathrm{OSH}$ concerns and promote healthy behavior.

Prior research has outlined indicators and metrics of integration that are important in TWH interventions, such as organizational leadership, data integration, organizational coordination across departments responsible for $\mathrm{OSH}$ and HP, and adequate resources (11). However, no research has evaluated these elements separately to determine whether (and to what extent) they contribute to intervention effectiveness beyond other factors, such as intervention content.

This article is part of a larger systematic review supported by the Agency for Healthcare Research and Quality (AHRQ) to inform a research agenda for the National Institutes of Health (NIH) 2015 Pathways to Prevention Workshop that focused on TWH. Our purpose was to evaluate evidence on the benefits and harms of TWH interventions.

\section{MeThods}

The NIH Pathways to Prevention Working Group provided the initial key questions (KQs). The RTI International-University of North Carolina Evidencebased Practice Center (EPC) further refined them and incorporated guidance from a technical expert panel into the final research protocol (see the Supplement, available at www.annals.org). The KQs concerned 1) populations, work settings, intervention types, and outcomes in studies of TWH interventions; 2 ) benefits and harms of interventions; 3 ) characteristics of effective interventions; 4) contextual factors potentially affecting intervention effectiveness; 5) research gaps; and 6) future research needs. Detailed methods and data for this review, including the analytic framework, search strategies, eligibility criteria, risk-of-bias (ROB) rating, and strength-of-evidence (SOE) grading methods, are available in the full report (12).

\section{Data Sources and Searches}

A research librarian searched MEDLINE, the Cochrane Library, the Cochrane Central Register of Controlled Trials, and PsycINFO from 1 January 1990 (reflecting the timing of increased attention and focus on integrated interventions) to 21 September 2015. We searched for relevant unpublished studies by using ClinicalTrials.gov and Academic Search Premier. To ensure that our database searches had not missed relevant citations, we used reference lists from pertinent reviews and a bibliography that we received from NIOSH listing studies relevant to the TWH program.

\section{Study Selection}

Two investigators independently reviewed abstracts and full-text articles against prespecified eligibility criteria (Appendix Table 1, available at www .annals.org). We included English-language studies of employed adults (aged $\geq 18$ years) that assessed any integrated intervention that met the definition of a TWH strategy (as defined earlier) (8). To be eligible for inclusion, an intervention had to be designed with the dual objective of improving workplace health and safety and overall health, health behaviors, or risk factors for chronic diseases. To assess the effectiveness and harms of interventions, we considered only studies with a concurrent control group comparing an integrated intervention with usual work practice, no intervention, or an active comparator (for example, an HP-only intervention or another integrated intervention that differed in content).

To address KQs related to the benefits and harms of interventions, we included commonly reported outcomes considered to be important measures of worker health and safety (Appendix Table 2, available at www .annals.org). To determine widespread and important outcomes in this body of literature, we reviewed prior studies of TWH interventions and requested input from technical expert panel members on our eligibility criteria before settling on the final research protocol. Final health outcomes included quality of life, functional status, and occupational illnesses and injuries, among others. Examples of intermediate outcomes were rates of smoking cessation, healthy eating behaviors, and outcomes related to hazardous workplace exposures. We also included use of health services and rates of workers' compensation and short-term disability claims. Finally, we searched for harms associated with TWH interventions, such as victim blaming and increased barriers to reporting work-related injuries or illnesses.

Study designs included randomized, controlled trials (RCTs); nonrandomized, controlled trials (NRCTs); and prospective cohort studies. In the full systematic review, we also included pre-post studies for some KQs (for example, to inform research gaps and future research needs). We included studies conducted in any workplace setting in a developed country ("very high" Human Development Index per the United Nations Development Programme) (13) to increase the applicability of our conclusions to U.S. worksites.

\section{Data Extraction and Quality Assessment}

We developed a template for evidence tables by using the PICOTS (population, intervention, comparator, outcomes, timing of outcomes measurement, and setting) framework and abstracted relevant information on characteristics of study populations, interventions, comparators, time frames, settings, study designs, methods, and results. One reviewer initially abstracted relevant data from each included article; a second team member reviewed each data abstraction against the original article for completeness and accuracy.

Two independent reviewers assessed the ROB for studies with a concurrent control group as low, medium, or high by using predefined criteria $(14,15)$. Discrepancies were resolved by consensus.

\section{Data Synthesis and Analysis}

We graded the SOE as high, moderate, low, or insufficient according to the AHRQ Methods Guide for Effectiveness and Comparative Effectiveness Reviews $(15,16)$. This approach incorporates 5 key domains: study limitations, directness, consistency, precision of the evidence, and reporting bias. We graded the SOE for an outcome only when at least 1 study that was 
rated as having low or medium $\mathrm{ROB}$ reported it; when we had at least 1 study rated as having medium ROB for a particular outcome, we used studies rated as having high ROB to assess the consistency of evidence when they reported the same outcomes in similar populations of workers. We did not attempt meta-analysis because of the heterogeneity of study designs, populations, interventions, and outcomes. Additional details on the SOE assessment are provided in the Appendix (available at www.annals.org).

\section{Role of the Funding Source}

The AHRQ funded the review; an NIH working group assisted in developing the review's scope. Neither agency had any role in the study selection, quality assessment, or data synthesis. The investigators are solely responsible for the content.

\section{RESULTS}

The Appendix Figure (available at www.annals.org) summarizes our literature search yields and selection decisions. Searches of all sources identified 1532 potentially relevant articles. After dual review of abstracts and full-text articles, we retained 24 studies (in 33 publications). Nine were single-group pre-post studies; these are omitted here but are described in the full review (12). Of the 15 included studies (in 23 publications) with concurrent control groups, 12 were RCTs $(10,17-35), 2$ were NRCTs $(36,37)$, and 1 was a prospective cohort study (38).

\section{Study Characteristics}

Across the 15 included studies, heterogeneity was substantial with regard to the work settings and populations, intervention types, and outcomes evaluated (Appendix Tables 2 and 3, available at www.annals .org). Most of the studies enrolled workers from 2 main sectors: manufacturing and construction industries (7 studies; participants were predominantly male, with a mix of blue-collar production workers and white-collar workers) and health care and social assistance industries (4 studies; participants were predominantly female nurses). Nine studies were done in the United States, 2 were done in the Netherlands, and 4 were done in Scandinavian countries. The average age of commonly targeted workers was 30 to 50 years. Few studies described the baseline health status of enrolled workers, including presence of chronic conditions. The OSH and HP interventions available at worksites (in addition to the intervention being studied) were generally not described.

All 15 studies assessed an intervention focused on an integrated objective (for example, addressing occupational hazards and promoting overall health). Six of the studies evaluated an intervention that involved strategic coordination across organizational departments or staff responsible for decision making related to OSH and $\operatorname{HP}(10,19,26,30,36,37)$. Most focused on developing a comprehensive program to promote worker health and safety informed by staff from various departments (for example, human resources, managers, OSH representatives, and HP representatives). Eleven studies evaluated an intervention that involved worker participation in its development, design, planning, or implementation $(10,19,22,24-26,29,31,33,36,38)$. The type and degree of participation varied across studies. Four studies assessed an intervention with both strategic integration and worker participation (10, $19,26,36$ ).

Most studies assessed complex multicomponent interventions; 3 evaluated a single-component intervention $(23,30,38)$. In terms of content, 1 study assessed the effectiveness of integration alone (without added OSH or HP content) (30). Of the 14 other included studies, 7 assessed interventions that included new, comprehensive OSH and HP components not previously available to workers $(10,19,24,26,29,32,36)$; 5 assessed interventions that included mostly HP content (tailored to the specific needs of workers) $(22,23$, $25,37,38)$; and 2 focused primarily on reducing occupational injuries, illnesses, or exposures (including work-life stress) and also included content promoting healthy behavior $(31,33)$.

Overall, studies measured a wide variety of outcomes (Appendix Table 2); few assessed the same outcomes in similar populations of workers. Of the 15 studies with a concurrent control group, we rated 5 RCTs as having medium $\operatorname{ROB}(25,26,31-33)$ and the other 10 studies as having high $\operatorname{ROB}(10,19,22-24,29,30,36-$ 38 ), primarily due to high rates of attrition and selection bias.

\section{Final Health and Safety Outcomes}

We were unable to grade SOE for any final health and safety outcome because of the diversity of outcomes measured and methodological shortcomings of the studies. Commonly assessed health outcomes included quality of life, work-related stress, and musculoskeletal symptoms. No study assessed work-related injuries or illness. Appendix Table 4 (available at www .annals.org) summarizes results of individual studies.

\section{Intermediate Outcomes}

Included studies assessed a wide range of intermediate health outcomes (Appendix Table 4). We were able to grade SOE for only 3 intermediate outcomes: smoking cessation, fruit and vegetable consumption, and sedentary work behavior. Results for these outcomes and our SOE grades are summarized in the Table.

Evidence from 2 RCTs rated as having either medium (25) or high (22) ROB supported the effectiveness of TWH interventions compared with no intervention for improving rates of smoking cessation (measured by 7-day abstinence rates) over 22 to 26 weeks (low SOE). Both were worksite RCTs comparing a multicomponent intervention featuring organizational integration and employee participation versus no intervention; one enrolled unionized construction laborers (25), and the other enrolled participants of a building and trade apprentice training program (22).

Three RCTs (all from the same research team) rated as having either medium $(25,26)$ or high $(10) \mathrm{ROB}$ mea- 


\begin{tabular}{|c|c|c|c|c|c|c|c|}
\hline $\begin{array}{l}\text { Population } \\
\text { (Reference) }\end{array}$ & $\begin{array}{l}\text { Intervention and } \\
\text { Comparator }\end{array}$ & $\begin{array}{l}\text { Time } \\
\text { Point, wk }\end{array}$ & Studies, $n$ & Participants, n & $\begin{array}{l}\text { Study } \\
\text { Limitations }\end{array}$ & Outcome and Results & $\begin{array}{l}\text { Strength of } \\
\text { Evidence }\end{array}$ \\
\hline $\begin{array}{l}\text { Construction (25) and } \\
\text { manufacturing (22) } \\
\text { workers }\end{array}$ & $\begin{array}{l}\text { Integrated } \\
\text { intervention vs. } \\
\text { no intervention }\end{array}$ & $22-26$ & 2 & 737 & $\begin{array}{l}\text { Medium or } \\
\text { high }\end{array}$ & $\begin{array}{l}\text { Self-reported 7-d smoking abstinence, } \\
\text { intervention vs. no intervention } \\
1 \mathrm{RCT}(n=188 \text { smokers and recent } \\
\text { quitters at baseline) rated as } \\
\text { having medium ROB ( } 25): 19 \% \\
\text { vs. } 8 \% \text { of workers at } 26 \text { wk; } \\
P=0.03^{*} \\
1 \text { RCT ( } n=490 \text { smokers at baseline) } \\
\text { rated as having high ROB ( } 22) \text { : } \\
26 \% \text { vs. } 17 \% \text { of workers at } 22 \\
\text { wk; } P=0.014\end{array}$ & $\begin{array}{l}\text { Low for } \\
\text { benefit }\end{array}$ \\
\hline $\begin{array}{l}\text { Manufacturing } \\
(19,26) \text { and } \\
\text { construction (25) } \\
\text { workers }\end{array}$ & $\begin{array}{l}\text { Integrated } \\
\text { intervention vs. } \\
\text { no intervention }\end{array}$ & $26-104$ & 3 & 6056 & $\begin{array}{l}\text { Medium or } \\
\text { high }\end{array}$ & $\begin{array}{l}\text { Self-reported fruit and vegetable } \\
\text { consumption, intervention vs. } \\
\text { no intervention } \\
2 \text { RCTs rated as having medium } \\
\text { ROB: } \\
1 \text { RCT }(n=578)(25) \text { : mean } \\
\text { change from baseline in } \\
\text { servings of fruits and } \\
\text { vegetables per day, } 1.52 \\
\text { (SD, 3.39) vs. }-0.09 \text { (SD, } 3.31) ; \\
P \leq 0.0001 \\
1 \text { RCT ( } n=3092)(26) \text { : mean } \\
\text { change from baseline in } \\
\text { number of workers consuming } \\
\geq 5 \text { servings of fruits and } \\
\text { vegetables per dayt, } 7.5 \% \text { vs. } \\
1.1 \% ; P=0.048 \\
1 \text { RCT ( } n=2386) \text { rated as having } \\
\text { high ROB }(10) \text { : mean change } \\
\text { from baseline in servings of } \\
\text { fruits and vegetables per day, } \\
0.22 \text { vs. } 0.09 ; P=0.04\end{array}$ & $\begin{array}{l}\text { Low for } \\
\text { benefit }\end{array}$ \\
\hline $\begin{array}{l}\text { Sedentary office } \\
\text { workers }(31,32)\end{array}$ & $\begin{array}{l}\text { Integrated } \\
\text { intervention vs. } \\
\text { any comparator }\end{array}$ & $16-52$ & 2 & 262 & Medium & $\begin{array}{l}\text { Sedentary activity at work, intervention } \\
\text { vs. comparator } \\
1 \mathrm{RCT}(n=412)(31) \text { : change in } \\
\text { minutes spent sedentary per } \\
\text { day (physical environment } \\
\text { intervention vs. control group), } \\
-57.9(95 \% \mathrm{Cl},-111.7 \text { to } 4.2) ; \\
P=0.03 \ddagger \\
1 \mathrm{RCT}(n=60)(32) \text { : change in } \\
\text { percentage of work time spent } \\
\text { sedentary (integrated } \\
\text { intervention } \S \text { vs. OSH-only } \\
\text { group), }-2.0(95 \% \mathrm{Cl},-4.4 \text { to } \\
0.3) \text { vs. }-0.4 \mathrm{Cl},-1.1 \text { to } 0.2) ; \\
P=0.08\end{array}$ & $\begin{array}{l}\text { Low for } \\
\text { benefit }\end{array}$ \\
\hline
\end{tabular}

$\mathrm{OSH}=$ occupational safety and health; RCT = randomized, controlled trial; ROB = risk of bias.

* This RCT also found benefit favoring the integrated intervention for rates of 7 -d abstinence from any tobacco use (19\% vs. $8 \%$; $P=0.005)(25)$. $\dagger$ In the overall sample of workers, intervention and control worksites did not differ (mean change from baseline in percentage consuming $\geq 5$ servings per day: $5.4 \%$ vs. $1.7 \% ; P=0.41$ ), and managers at intervention worksites reported decreased consumption of fruits and vegetables compared with managers at control worksites (mean change from baseline in percentage consuming $\geq 5$ servings per day: $-5.5 \%$ vs. $3.6 \%$; $P=$ $0.048)(26)$.

‡ The other 2 active comparators (social environmental intervention and combined social and physical environmental intervention) and the control group did not differ on any measure of work-specific physical activity or sedentary behavior outcome (31).

$\S$ Workers were randomly assigned to an ergonomic workstation optimization intervention alone or an integrated intervention that included the same ergonomic intervention plus access to a seated activity-permissive workstation (32).

sured changes in fruit and vegetable intake among U.S. manufacturing or construction workers who were randomly assigned to a multicomponent integrated intervention or no intervention. Evidence from these 3 RCTs supported the effectiveness of TWH interventions compared with no intervention for improving fruit and vegetable consumption over 26 to 104 weeks (low SOE).

Finally, findings from 2 RCTs rated as having medium ROB $(31,32)$ supported the effectiveness of TWH interventions (compared with any comparator pro-

www.annals.org gram) for reducing sedentary behavior at work over 16 to 52 weeks (low SOE). One RCT enrolled Dutch office workers employed at a financial institution, with departments randomly assigned to 1 of the following 4 groups: no intervention control group, social environment intervention, physical environment intervention, or combined social and physical environment intervention (31). At 52 weeks, workers in the physical environment group decreased sedentary behavior at work compared with the control group. The second RCT $(n=$ 
60) randomly assigned sedentary office workers to a workstation optimization intervention (ergonomic assessment, education, and prompts to promote breaks and posture variation) plus access to a seated activitypermissive workstation (TWH intervention) or to the workstation optimization intervention alone (32). At 16 weeks, workers randomly assigned to the TWH intervention reduced the percentage of time spent engaging in sedentary behavior compared with those assigned to the ergonomic intervention alone, but the difference between groups was not statistically significant (33).

Evidence was insufficient for the following intermediate outcomes (because of unknown consistency due to their being reported by a single study rated as having medium ROB): blood pressure, weight, overall and work-specific levels of physical activity, consumption of red meat, safety behaviors, and safety compliance.

\section{Utilization Outcomes and Occupational Injury and Illness Surveillance Outcomes}

No study rated as having low or medium ROB assessed rates of health care utilization or occupational injury and illness surveillance outcomes. One NRCT $(n=519)$ rated as having high ROB (37) found no significant difference between intervention and control U.S. automotive manufacturing worksites in the percentages of workers who had 1 or more workers' compensation claims and short-term disability claims at 28 weeks.

\section{Harms}

Two studies, both rated as having high $\mathrm{ROB}$, investigated potential harms that were not prespecified. One cohort study $(n=172)$ enrolling Danish inpatient nurses evaluated an intervention aimed at improving shift work scheduling compared with no intervention; participants in the intervention group judged the intervention schedule as having a worse effect on family life at 52 weeks than the preintervention schedule (38). One RCT $(n=860)$ enrolling Norwegian postal workers assessed potential harms in a 4-group study that compared an integrated intervention with aerobic exercise alone, stress management alone, or no intervention (29). Participants reported no subjective negative effects of the intervention on work environment, work situation, and other factors at 12 and 52 weeks, but the study did not present quantitative results (29).

\section{Characteristics of Effective Interventions}

We evaluated common characteristics of interventions that were effective for improving any outcomes for which we were able to grade the SOE for benefit (Table). Effective interventions were heterogeneous; separating individual components from the overall types (or "bundles") of interventions that showed efficacy was not possible.

In 5 of the 6 studies contributing to our SOE grades, worker participation informed the development, design, planning, or implementation of the interventions. Two studies set in manufacturing worksites $(10,26)$ involved the creation of a joint worker-manage- ment employee advisory board comprising workers, production managers, and representatives from the health and safety and human resources departments, who planned and implemented the intervention in partnership with the study investigators. Employee advisory board members gave input on specific components; for example, policies aimed at reducing hazardous occupational exposure were cowritten by the study investigators and workplace managers (26). In 3 studies, the intervention was designed based on input (or prior research) from members of the targeted occupational group (for example, related to culture, potential occupational exposures, or work experience) $(22,25,31)$; in 2 of these studies, the intervention was implemented in collaboration with union members or support from apprenticeship program leaders $(22,25)$. Most effective interventions tailored their components or materials to cultural or social aspects of the worker population (for example, to workers with low literacy skills). All effective interventions were complex multicomponent interventions that reinforced messages about health and safety through multiple levels of influence or multiple methods of delivery (or both) over time.

\section{Contextual Factors}

We abstracted data from included studies that related to contextual factors that the original authors identified as potential modifiers of intervention effectiveness. We included factors that investigators had noted in their results (such as whether the intervention was more or less effective at worksites that differed by a specific contextual factor) and factors mentioned in the discussion that could have facilitated or hindered effectiveness.

Few studies identified contextual factors that could have played a role in influencing intervention effectiveness. Work organization and union membership status were the 2 most commonly mentioned factors. Others mentioned in at least 1 study included health insurance status or access to primary care services, support from higher management, availability of resources, and employee stress or strain related to company downsizing during the intervention period.

\section{Discussion}

Overall, the body of evidence supporting the effectiveness of integrating $\mathrm{OSH}$ and HP efforts was small and heterogeneous in terms of populations, interventions, and measured outcomes; for some areas of interest, evidence was nonexistent. The evidence from controlled studies is shown in Appendix Table 4, and our SOE grades for smoking cessation, fruit and vegetable consumption, and sedentary work behavior are summarized in the Table. The small size of the body of evidence (15 studies with concurrent control groups) is not surprising given that the concept of integration is relatively new. The body of evidence about TWH interventions may reasonably be expected to grow over the next few years. 
Findings graded as having low SOE supported the effectiveness of TWH interventions for increasing rates of smoking cessation over 22 to 26 weeks, increasing fruit and vegetable intake over 26 to 104 weeks, and reducing sedentary work behavior over 16 to 52 weeks. Evidence was insufficient to assess the effectiveness of integrated interventions for improving quality of life, stress, blood pressure, weight, overall and workspecific levels of physical activity, consumption of red meat, safety behaviors, and safety compliance. Effective interventions were informed by worker participation and included comprehensive program content that highlighted the potential additive or synergistic risks of hazardous workplace exposures and health behavior.

We found no eligible studies with a concurrent control group that reported on the incidence of injuries or chronic diseases (including work-related injuries and illnesses) or on the harms of interventions. Many studies had methodological limitations, such as high attrition and no statistical methods to control for baseline differences between groups. Outcomes were assessed over a relatively short period; only 4 of the 15 studies measured outcomes beyond 1 year.

We did not identify any previous systematic review in our search (MEDLINE, the Cochrane Library, the Cochrane Central Register of Controlled Trials, and PsycINFO from 1 January 1990 to 21 September 2015) that was similar in scope or that graded the SOE related to common outcomes reported in studies of TWH. One prior systematic review (39) and one expert (or narrative) review (40) did provide a broad overview of TWH interventions. The results of our review are generally consistent with those of previous reviews with respect to conclusions about the limitations of the evidence base. For example, Anger and colleagues noted that integrated interventions improved risk factors for chronic diseases. They concluded, however, that the evidence that integration itself confers a significant benefit is lacking and is "perhaps the most glaring gap in the TWH literature" (39).

During our review process, we systematically abstracted key factors (identified a priori) that may affect the applicability of the evidence base. We focused on issues for populations of workers and worksites in the United States. Studies demonstrating the effectiveness of TWH interventions for improving rates of smoking cessation or increasing the consumption of fruits and vegetables involved U.S. blue-collar workers and used survey data collected before 2004; these investigations all came from the same group of researchers $(10,19$, $25,26)$.

Our review had limitations beyond those already noted. The most critical may be the lack of consistent terminology related to TWH interventions. As of November 2015, the definition of TWH had shifted from a relatively narrow focus on integrating $\mathrm{OSH}$ and $\mathrm{HP}$ to "an approach [that] advocates for a holistic understanding of the factors that contribute to worker well-being" (8). Also, reporting or description of intervention components in some studies was potentially inadequate. For these reasons, we may have overlooked some stud- ies that could be considered related to TWH interventions. To address this deficiency, we solicited and received a database from NIOSH that listed studies deemed relevant to TWH. Our search strategies had identified the vast majority of these studies. Nevertheless, some studies that we excluded might still be considered related to $\mathrm{TWH}$.

Publication bias and selective reporting of outcomes are other potential limitations. Although we searched for unpublished trials and outcomes, we did not find direct evidence of either of these biases. We excluded non-English-language studies largely because of limitations in time and resources. However, we identified such studies in our searches and did not see any references that seemed to meet our eligibility criteria. Searches of the NIOSH references did not uncover any non-English-language studies. Given this, and given the fact that TWH is a relatively new strategy, we believe that limiting our review to English-language studies had little effect.

Workplace OSH and HP programs are likely to have improved since the mid-2000s. Whether the results of these trials would apply to worksites that have active HP programs or robust policies that promote smoking cessation and healthy eating is not clear. In other words, integrated OSH and HP initiatives may not add much to strong efforts already in place. They may, however, be models for industries or worksites that currently lack such policies or programs.

Moreover, relatively recent changes in health policy or practice, such as community-based health interventions and health care, may also limit the applicability of TWH studies published 10 or more years ago. For example, smoking cessation services may be more widely available because of these changes than they were a decade or more ago.

Additional adequately powered multisite RCTs or other prospective studies with a concurrent control group are needed to replicate encouraging findings that have been observed in only a few trials to date. In addition, future studies need to be designed explicitly to assess the benefits of integration separate from new $\mathrm{OSH}$ or HP components not previously offered at worksites. Including a broader range of workers in future studies could increase the applicability of TWH interventions and enable reviewers to assess the consistency of findings. It might also answer the question of whether integrated strategies are or are not more effective in groups of workers who differ by demographic, social, or occupational characteristics that contribute to adverse health outcomes. In terms of methods, investigators should plan for high attrition (and use methods to address missing data when necessary) and should provide a clear flow diagram to show the flow of participants from group assignments through the final analysis.

In conclusion, evidence was insufficient to assess the effectiveness of integrated interventions for improving various health outcomes that matter for worker populations, such as quality of life, levels of stress, and rates of injuries. With respect to intermediate outcomes 
relating more to work safety factors, we also had little or no information about TWH effects on safety behaviors and safety compliance. Insofar as physicians and other health professionals are concerned with such risk factors as tobacco use, diet and nutrition, and sedentary lifestyles, our findings are encouraging. Although evidence was meager, it does point to the utility of integrated TWH interventions that include efforts to encourage smoking cessation, consumption of more fruits and vegetables, and less sedentary work. Health professionals should understand the relationship between working conditions and overall health, such as how working conditions can promote or act as a barrier to healthy behavior. Recognizing the synergy between $\mathrm{OSH}$ and HP may increase the relevance of health recommendations and potentially promote employee participation in workplace programs.

From University of North Carolina at Chapel Hill, Chapel Hill, and RTI International, Research Triangle Park, North Carolina.

Disclaimer: The authors of this manuscript are responsible for its content. Statements in the manuscript should not be construed as endorsement by the AHRQ or the U.S. Department of Health and Human Services. The AHRQ retains a license to display, reproduce, and distribute the data and the report from which this manuscript was derived under the terms of the Agency's contract with the author.

Acknowledgment: The authors thank Carol Woodell of RTI International for her project management expertise; Loraine Monroe of RTI International for formatting the technical report; and Kim Wittenberg, MA, AHRQ Task Order Officer, for her support, commitment, and contributions.

Financial Support: This project was funded under contract 290-2012-00008-I_HHSA 29032009T from AHRQ, U.S. Department of Health and Human Services.

Disclosures: Dr. Cluff reports funding from the Centers for Disease Control and Prevention outside the submitted work. Dr. Viswanathan reports a contract with RTI International during the conduct of the study. Dr. Lohr reports contracts with the Agency for Healthcare Research and Quality outside the submitted work. Authors not named here have disclosed no conflicts of interest. Disclosures can also be viewed at www .acponline.org/authors/icmje/ConflictOflnterestForms.do?ms Num=M16-0626.

Reproducible Research Statement: Study protocol: Available in the Supplement or at https://effectivehealthcare.ahrq.gov /ehc/products/611/2085/worker-health-protocol-150526.pdf. Statistical code: Not applicable. Data set: Available at http: //srdr.ahrq.gov/projects/620.

Requests for Single Reprints: Cynthia Feltner, MD, MPH, Department of Medicine, University of North Carolina at Chapel Hill, 5034 Old Clinic Building, CB 7110, PO Box 12194, Chapel Hill, NC 27599; e-mail, cindy_feltner@med.unc.edu.

Current author addresses and author contributions are available at www.annals.org.

\section{References}

1. Hymel PA, Loeppke RR, Baase CM, Burton WN, Hartenbaum NP, Hudson TW, et al. Workplace health protection and promotion: a new pathway for a healthier-and safer-workforce. J Occup Environ Med. 2011;53:695-702. [PMID: 21654443] doi:10.1097/JOM.0b013 e31822005d0

2. Leigh JP, Markowitz SB, Fahs M, Shin C, Landrigan PJ. Occupational injury and illness in the United States. Estimates of costs, morbidity, and mortality. Arch Intern Med. 1997;157:1557-68. [PMID: 9236557]

3. Dembe AE. The social consequences of occupational injuries and illnesses. Am J Ind Med. 2001;40:403-17. [PMID: 11598991]

4. Bureau of Labor Statistics. Employer-reported workplace injuries and illnesses-2014 [press release]. 29 October 2015. Accessed at www.bls.gov/news.release/osh.nrO.htm on 8 April 2016.

5. Mokdad AH, Marks JS, Stroup DF, Gerberding JL. Actual causes of death in the United States, 2000. JAMA. 2004;291:1238-45. [PMID: 15010446]

6. World Health Organization. Jakarta statement on healthy workplaces. 1997 [updated 12 December 2010]. Accessed at www who.int/healthpromotion/conferences/previous/jakarta/statements /workplaces/en on 8 April 2016.

7. Centers for Disease Control and Prevention. Total Worker Health. 2013 [updated 9 February 2016]. Accessed at www.cdc.gov/niosh /twh on 8 April 2016.

8. Centers for Disease Control and Prevention. Guidelines for implementing Total Worker Health programs. 2013 [updated 26 August 2015]. Accessed at www.cdc.gov/niosh/twh/reports.html on 8 April 2016.

9. National Institute for Occupational Safety and Health. Research Compendium: The NIOSH Total Worker Health Program: Seminal Research Papers. Publication no. 2012-146. Washington, DC: U.S. Department of Health and Human Services; 2012 [updated 6 June 2014].

10. Sorensen G, Stoddard A, Hunt MK, Hebert JR, Ockene JK, Avrunin JS, et al. The effects of a health promotion-health protection intervention on behavior change: the WellWorks Study. Am J Public Health. 1998;88:1685-90. [PMID: 9807537]

11. Williams JA, Nelson CC, Cabán-Martinez AJ, Katz JN, Wagner GR, Pronk NP, et al. Validation of a new metric for assessing the integration of health protection and health promotion in a sample of small- and medium-sized employer groups. J Occup Environ Med. 2015;57:1017-21. [PMID: 26340291] doi:10.1097/JOM.0000000 000000521

12. Feltner C, Peterson K, Palmieri Weber R, Cluff L, CokerSchwimmer E, Viswanathan M, et al. Total Worker Health. Comparative Effectiveness Review no. 175. (Prepared by RTI InternationalUniversity of North Carolina Evidence-based Practice Center under contract 290-2012-00008-I_HHSA 29032009T.) Rockville, MD: Agency for Healthcare Research and Quality; 2015.

13. United Nations Development Programme. Human development report 2014-sustaining human progress: reducing vulnerabilities and building resilience. 2014. Accessed at http://hdr.undp.org/en /2014-report on 8 April 2016.

14. Viswanathan M, Berkman ND, Dryden DM, Hartling L. Assessing Risk of Bias and Confounding in Observational Studies of Interventions or Exposures: Further Development of the RTI Item Bank. Methods Research Report. (Prepared by RTI-University of North Carolina Evidence-based Practice Center under contract 290-2007-10056-I.) Rockville, MD: Agency for Healthcare Research and Quality; 2013. 15. Agency for Healthcare Research and Quality. Methods Guide for Effectiveness and Comparative Effectiveness Reviews. Rockville, MD: Agency for Healthcare Research and Quality; 2014 [updated 26 February 2015].

16. Berkman ND, Lohr KN, Ansari MT, Balk EM, Kane R, McDonagh $M$, et al. Grading the strength of a body of evidence when assessing health care interventions: an EPC update. J Clin Epidemiol. 2015;68: 1312-24. [PMID: 25721570] doi:10.1016/j.jclinepi.2014.11.023

17. Sorensen G, Stoddard A, Ockene JK, Hunt MK, Youngstrom R. Worker participation in an integrated health promotion/health pro- 
tection program: results from the WellWorks project. Health Educ $\mathrm{Q}$. 1996;23:191-203. [PMID: 8744872]

18. Sorensen G, Himmelstein JS, Hunt MK, Youngstrom R, Hebert JR, Hammond SK, et al. A model for worksite cancer prevention: integration of health protection and health promotion in the WellWorks Project. Am J Health Promot. 1995;10:55-62. [PMID: 10155659]

19. Sorensen G, Stoddard AM, LaMontagne AD, Emmons K, Hunt MK, Youngstrom R, et al. A comprehensive worksite cancer prevention intervention: behavior change results from a randomized controlled trial (United States). J Public Health Policy. 2003;24:5-25. [PMID: 12760241]

20. Lamontagne AD, Stoddard AM, Youngstrom RA, Lewiton M, Sorensen G. Improving the prevention and control of hazardous substance exposures: a randomized controlled trial in manufacturing worksites. Am J Ind Med. 2005;48:282-92. [PMID: 16142731]

21. Hunt MK, Lederman R, Stoddard AM, LaMontagne AD, McLellan $D$, Combe $C$, et al. Process evaluation of an integrated health promotion/occupational health model in WellWorks-2. Health Educ Behav. 2005;32:10-26. [PMID: 15642751]

22. Okechukwu CA, Krieger N, Sorensen G, Li Y, Barbeau EM. MassBUILT: effectiveness of an apprenticeship site-based smoking cessation intervention for unionized building trades workers. Cancer Causes Control. 2009;20:887-94. [PMID: 19301135] doi:10.1007 /s10552-009-9324-0

23. Palumbo MV, Wu G, Shaner-McRae H, Rambur B, Mclntosh B. Tai Chi for older nurses: a workplace wellness pilot study. Appl Nurs Res. 2012;25:54-9. [PMID: 20974089] doi:10.1016/j.apnr.2010.01 .002

24. Tveito TH, Eriksen HR. Integrated health programme: a workplace randomized controlled trial. J Adv Nurs. 2009;65:110-9. [PMID: 19032505] doi:10.1111/j.1365-2648.2008.04846.x

25. Sorensen G, Barbeau EM, Stoddard AM, Hunt MK, Goldman R, Smith A, et al. Tools for health: the efficacy of a tailored intervention targeted for construction laborers. Cancer Causes Control. 2007;18: 51-9. [PMID: 17186421]

26. Sorensen G, Barbeau E, Stoddard AM, Hunt MK, Kaphingst K, Wallace L. Promoting behavior change among working-class, multiethnic workers: results of the Healthy Directions-Small Business study. Am J Public Health. 2005;95:1389-95. [PMID: 16006422] 27. Hunt MK, Barbeau EM, Lederman R, Stoddard AM, Chetkovich C, Goldman R, et al. Process evaluation results from the Healthy Directions-Small Business study. Health Educ Behav. 2007;34:90107. [PMID: 16740502]

28. Barbeau E, Roelofs C, Youngstrom R, Sorensen G, Stoddard A, LaMontagne AD. Assessment of occupational safety and health programs in small businesses. Am J Ind Med. 2004;45:371-9. [PMID: 15029570]

29. Eriksen HR, Ihlebaek C, Mikkelsen A, Grønningsaeter H, Sandal $\mathrm{GM}$, Ursin H. Improving subjective health at the worksite: a random- ized controlled trial of stress management training, physical exercise and an integrated health programme. Occup Med (Lond). 2002;52: 383-91. [PMID: 12422025]

30. von Thiele Schwarz U, Augustsson H, Hasson H, Stenfors-Hayes T. Promoting employee health by integrating health protection, health promotion, and continuous improvement: a longitudinal quasi-experimental intervention study. J Occup Environ Med. 2015; 57:217-25. [PMID: 25654524] doi:10.1097/JOM.00000000000 00344

31. Coffeng JK, Boot CR, Duijts SF, Twisk JW, van Mechelen W, Hendriksen IJ. Effectiveness of a worksite social \& physical environment intervention on need for recovery, physical activity and relaxation; results of a randomized controlled trial. PLoS One. 2014;9: e114860. [PMID: 25542039] doi:10.1371/journal.pone.0114860 32. Carr LJ, Leonhard C, Tucker S, Fethke N, Benzo R, Gerr F. Total Worker Health intervention increases activity of sedentary workers. Am J Prev Med. 2016;50:9-17. [PMID: 26260492] doi:10.1016/j. amepre.2015.06.022

33. Hammer LB, Truxillo DM, Bodner T, Rineer J, Pytlovany AC, Richman A. Effects of a workplace intervention targeting psychosocial risk factors on safety and health outcomes. Biomed Res Int. 2015; 2015:836967. [PMID: 26557703] doi:10.1155/2015/836967

34. Coffeng JK, Hendriksen IJ, van Mechelen W, Boot CR. Process evaluation of a worksite social and physical environmental intervention. J Occup Environ Med. 2013;55:1409-20. [PMID: 24270291] doi: 10.1097/JOM.0b013e3182a50053

35. Coffeng JK, Hendriksen IJ, Duijts SF, Proper KI, van Mechelen W, Boot CR. The development of the Be Active \& Relax "Vitality in Practice" (VIP) project and design of an RCT to reduce the need for recovery in office employees. BMC Public Health. 2012;12:592. [PMID: 22852835] doi:10.1186/1471-2458-12-592

36. Maes S, Verhoeven C, Kittel F, Scholten H. Effects of a Dutch work-site wellness-health program: the Brabantia Project. Am J Public Health. 1998;88:1037-41. [PMID: 9663150]

37. Allen HM Jr, Borden S 4th, Pikelny DB, Paralkar S, Slavin T, Bunn WB 3rd. An intervention to promote appropriate management of allergies in a heavy manufacturing workforce: evaluating health and productivity outcomes. J Occup Environ Med. 2003;45:956-72. [PMID: 14506339]

38. Bøggild H, Jeppesen HJ. Intervention in shift scheduling and changes in biomarkers of heart disease in hospital wards. Scand J Work Environ Health. 2001;27:87-96. [PMID: 11409601]

39. Anger WK, Elliot DL, Bodner T, Olson R, Rohlman DS, Truxillo DM, et al. Effectiveness of Total Worker Health interventions. J Occup Health Psychol. 2015;20:226-47. [PMID: 25528687] doi:10 $.1037 / \mathrm{a} 0038340$

40. Pronk NP. Integrated worker health protection and promotion programs: overview and perspectives on health and economic outcomes. J Occup Environ Med. 2013;55:S30-7. [PMID: 24284747] doi: 10.1097/JOM.0000000000000031 
Current Author Addresses: Dr. Feltner: Department of Medicine, University of North Carolina at Chapel Hill, 5034 Old Clinic Building, CB 7110, PO Box 12194, Chapel Hill, NC 27599.

Drs. Peterson, Cluff, Viswanathan, and Lohr: Workplace Health and Safety, RTI International, 3040 Cornwallis Road, PO Box 12194, Research Triangle Park, NC 27709-2194.

Dr. Palmieri Weber and Mr. Coker-Schwimmer: RTI-UNC Evidence-based Practice Center, Cecil G. Sheps Center for Health Services Research, University of North Carolina at Chapel Hill, 725 Martin Luther King Jr. Boulevard, CB 7590, Chapel Hill, NC 27599.

Author Contributions: Conception and design: C. Feltner, K. Peterson, R. Palmieri Weber, M. Viswanathan.

Analysis and interpretation of the data: C. Feltner, K. Peterson, R. Palmieri Weber, L. Cluff, M. Viswanathan, K.N. Lohr.

Drafting of the article: C. Feltner, K. Peterson, R. Palmieri Weber, E. Coker-Schwimmer, K.N. Lohr.

Critical revision of the article for important intellectual content: C. Feltner, K. Peterson, R. Palmieri Weber, E. CokerSchwimmer, M. Viswanathan, K.N. Lohr.

Final approval of the article: C. Feltner, K. Peterson, R. Palmieri Weber, L. Cluff, E. Coker-Schwimmer, M. Viswanathan, K.N. Lohr.

Provision of study materials or patients: R. Palmieri Weber. Statistical expertise: C. Feltner, R. Palmieri Weber.

Obtaining of funding: C. Feltner, M. Viswanathan.

Administrative, technical, or logistic support: C. Feltner, R.

Palmieri Weber, E. Coker-Schwimmer, M. Viswanathan.

Collection and assembly of data: C. Feltner, K. Peterson, R. Palmieri Weber, L. Cluff, E. Coker-Schwimmer.

\section{ApPENDIX: SOE Assessment}

We graded the SOE of the accumulated evidence on a given issue to answer the specific KQs on the benefits and harms of the interventions in this review; we used the guidance established for the EPC program (16). Developed to grade the overall strength of a body of evidence, this approach now incorporates 5 key do- mains: study limitations (including study design and aggregate $R O B$ ), consistency, directness, precision of the evidence, and reporting bias. It also considers other optional domains that may be relevant for some scenarios, such as plausible confounding that would decrease the observed effect and strength of association (that is, magnitude of effect).

Appendix Table 5 describes the evidence grades that can be assigned. Grades reflect the strength of the body of evidence to answer outcomes relevant to KQ2 (comparative effectiveness, efficacy, and harms of the interventions in this review). Two reviewers assessed each domain for each key outcome, and differences were resolved by consensus. For each assessment, 1 of the 2 reviewers was an experienced EPC investigator.

An unfavorable assessment for any of the 4 key domains (inconsistency, indirectness, imprecision, or medium aggregate $\mathrm{ROB}$ ) typically resulted in downgrading from high to moderate SOE. Two unfavorable assessments typically resulted in downgrading to low SOE. When only 1 study reported an outcome of interest (with unknown consistency and imprecision), we usually graded the SOE as insufficient; when similar interventions had consistent results in different populations of workers or at different outcome timings, we graded the SOE as low. Appendix D of the full review presents tables (see Appendix Tables 6 to 14) showing our assessments for each domain and the resulting $\mathrm{SOE}$ grades for outcomes eligible for $\mathrm{KQ} 2$, organized by outcome category.

\section{Web-Only Reference}

41. Sorensen G, McLellan D, Dennerlein JT, Pronk NP, Allen JD, Boden $\mathrm{LI}$, et al. Integration of health protection and health promotion: rationale, indicators, and metrics. J Occup Environ Med. 2013 Dec;55(12 Suppl):S12-8. [PMID: 24284762] doi:10.1097/JOM.00000 00000000032 




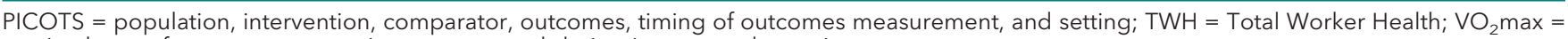
maximal rate of oxygen consumption as measured during incremental exercise.

*Variations in the degree to which interventions are "integrated" and how integration is accomplished, as well as the specific intervention components included, are considered characteristics of the integrated interventions and are the focus of key question 1 (characteristics of interventions) and key question 3 (characteristics of effective interventions).

+ Occupational safety and health: Intervention (or program) components aimed at reducing hazardous exposures at work that can lead to workrelated injury, illness, and disability. Interventions can be at the organizational or individual level (or both). Examples include (but are not limited to) the following: employer policies to improve (or remove) work hazards, engineering controls designed to eliminate or substitute hazards, adoption of improved personal protective equipment, and individual-level health and safety training to employees.

$\ddagger$ Worksite health promotion: Intervention (or program) components aimed at promoting worker health by decreasing risk factors for chronic diseases (e.g., smoking, sedentary behavior, obesity, blood pressure, and others), improving stress, and promoting overall well-being (e.g., via social support or physical activity). Intervention components may incorporate employee assistance programs, clinical prevention services, disease management programs, and other health benefits. Interventions may also include community-based services (e.g., referral for community-based health services) or environmental changes (e.g., increasing access to healthy foods at a worksite).

$\S$ We included pre-post studies for some descriptive key questions in the full report and to inform future research needs (12). 


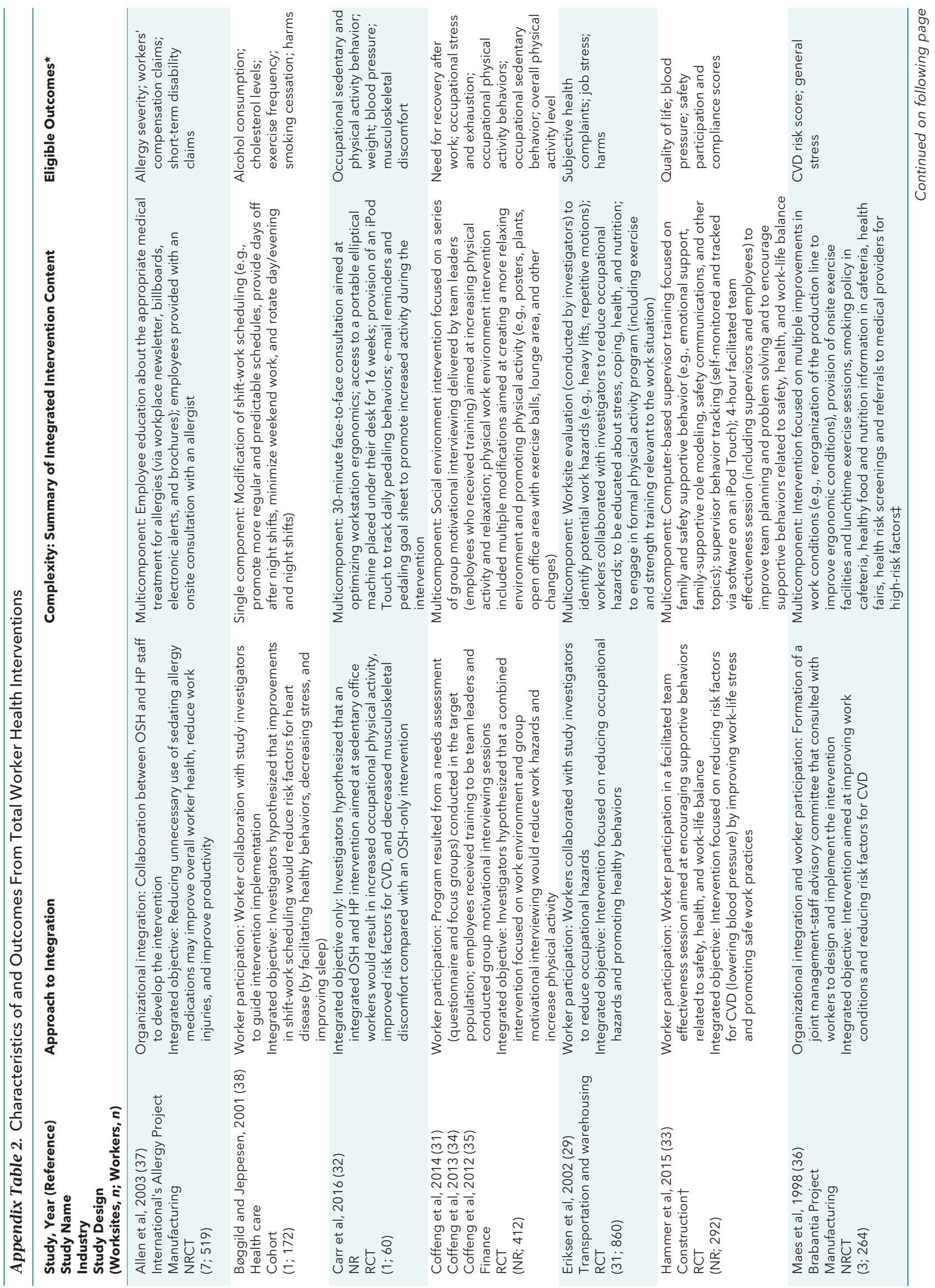

www.annals.org 


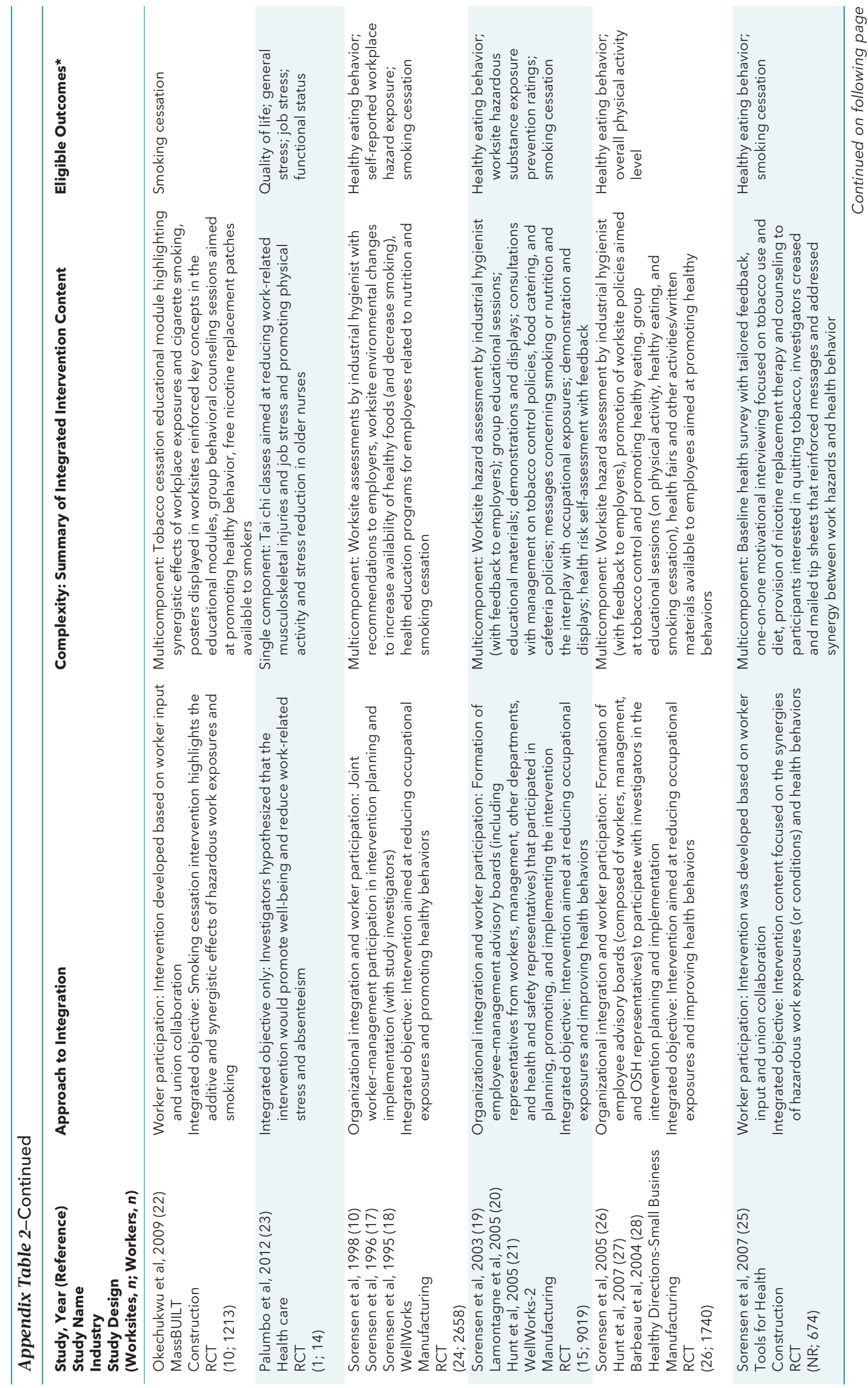






www.annals.org 
Appendix Figure. Disposition of articles for systematic evidence review of Total Worker Health interventions.



NIOSH = National Institute for Occupational Safety and Health; PICOTS = population, intervention, comparator, outcomes, timing of outcomes measurement, and setting.

* ClinicalTrials.gov and Academic Search Premier. 


\begin{tabular}{|c|c|c|c|c|c|}
\hline $\begin{array}{l}\text { Allen et al, } 2003(37) \\
\text { International's Allergy } \\
\text { Project }\end{array}$ & $\begin{array}{l}\text { Manufacturing } \\
\text { Worksites producing medium- and heavy-duty } \\
\text { trucks and diesel engines } \\
(7 ; 519) \\
\text { United States (Illinois, Indiana) }\end{array}$ & $\begin{array}{l}\text { Blue-collar production workers and } \\
\text { while-collar workers (percentage } \\
\text { across worksites NR) }\end{array}$ & 43-46 (NR) & 31 & NR \\
\hline Carr et al, 2016 (32) & $\begin{array}{l}\text { NR } \\
\text { Private company } \\
(1 ; 60) \\
\text { United States (lowa) }\end{array}$ & $\begin{array}{l}\text { Sedentary desk job workers at a } \\
\text { private companyt }\end{array}$ & $45(11)$ & 70 & $4-15$ \\
\hline $\begin{array}{l}\text { Coffeng et al, } 2014(31) \\
\text { Coffeng et al, } 2013(34) \\
\text { Coffeng et al, } 2012(35)\end{array}$ & $\begin{array}{l}\text { Finance } \\
\text { Departments of a financial service provider } \\
\text { (NR; } 412 \text { ) } \\
\text { The Netherlands }\end{array}$ & $\begin{array}{l}\text { Office employees with mainly desk } \\
\text { jobs }\end{array}$ & $38-44(9.2-10.5)$ & $38-45$ & NR \\
\hline Hammer et al, 2015 (33) & $\begin{array}{l}\text { Multiple industries } \\
\text { Workers employed by a municipal public } \\
\text { works department } \\
\text { (NR; } 292 \text { ) } \\
\text { United States (state NR) }\end{array}$ & $\begin{array}{l}\text { Construction and utility workers, } \\
\text { including electricians, plumbers, } \\
\text { carpenters, heavy equipment } \\
\text { operators, sidewalk repair } \\
\text { persons, and others }\end{array}$ & $45(9.6)$ & 10 & 21 \\
\hline $\begin{array}{l}\text { Maes et al, } 1998 \text { (36) } \\
\text { Brabantia Project }\end{array}$ & $\begin{array}{l}\text { Manufacturing } \\
\text { Producer of household goods } \\
\text { (3;264) } \\
\text { The Netherlands }\end{array}$ & Blue-collar production workers & $39-41(10.4-10.5)$ & NR & NR \\
\hline $\begin{array}{l}\text { Okechukwu et al, } \\
2009 \text { (22) } \\
\text { MassBUILT }\end{array}$ & $\begin{array}{l}\text { Construction } \\
\text { Building trade apprentice training program } \\
\text { (10; } 1213 \text { ) } \\
\text { United States (Massachusetts) }\end{array}$ & $\begin{array}{l}\text { Apprentice training participants } \\
\text { (boilermakers, bricklayers, } \\
\text { electricians, hoisting and } \\
\text { portable engineers, ironworkers, } \\
\text { painters, plumbers, pipefitters, } \\
\text { and others) }\end{array}$ & $28-29(6.7-6.9)$ & $4-6$ & $15-18$ \\
\hline Palumbo et al, 2012 (23) & $\begin{array}{l}\text { Health care and service } \\
\text { Hospital (academic medical center) } \\
(1 ; 14) \\
\text { United States (Vermont) }\end{array}$ & $\begin{array}{l}\text { Registered nurses, licensed } \\
\text { practical nurses on hospital } \\
\text { wards requiring patient lifting }\end{array}$ & $\geq 49 \ddagger$ & 100 & NR \\
\hline $\begin{array}{l}\text { Sorensen et al, } 2005(26) \\
\text { Hunt et al, } 2007 \text { ( 27) } \\
\text { Barbeau et al, } \\
2004 \text { ( } 28) \\
\text { Healthy Directions-Small } \\
\text { Business }\end{array}$ & $\begin{array}{l}\text { Manufacturing } \\
\text { Worksites producing medical equipment, dog } \\
\text { food, specialty pumps, textiles, and } \\
\text { electronics; and laundry and printing } \\
\text { service providers } \\
(26 ; 1740) \\
\text { United States (Massachusetts) }\end{array}$ & $\begin{array}{l}\text { Blue-collar workers (83\%-84\%) and } \\
\text { managers }(16 \%-18 \%)\end{array}$ & 43-44 (NR) & $25-44$ & $18-25$ \\
\hline $\begin{array}{l}\text { Sorensen et al, } 2007 \text { (25) } \\
\text { Tools for Health }\end{array}$ & $\begin{array}{l}\text { Construction } \\
\text { Workers with membership in the Laborers' } \\
\text { International Union of North America } \\
\text { (NA; 674) } \\
\text { United States (multiple states) }\end{array}$ & $\begin{array}{l}\text { General laborers, concrete } \\
\text { workers, heavy construction } \\
\text { workers, demolition workers, } \\
\text { jackhammer }\end{array}$ & $40-41(9.5-9.7)$ & $5-6$ & $30-37$ \\
\hline $\begin{array}{l}\text { Tveito and Eriksen, } \\
2009(24)\end{array}$ & $\begin{array}{l}\text { Health care and social service } \\
\text { One nursing home for older people } \\
(1 ; 40) \\
\text { Norway }\end{array}$ & $\begin{array}{l}\text { Nursing auxiliaries, nurses, } \\
\text { assistants, other helping staff }\end{array}$ & NR & 100 & NR \\
\hline $\begin{array}{l}\text { von Thiele Schwarz et al, } \\
2015(30)\end{array}$ & $\begin{array}{l}\text { Health care and social service } \\
\text { Inpatient units }(12) \text { in one county hospital } \\
(1 ; 312) \\
\text { Sweden }\end{array}$ & $\begin{array}{l}\text { Registered nurses, assistant nurses, } \\
\text { others with direct patient care }\end{array}$ & $45-47(9.2-12.1)$ & $91-96$ & NR \\
\hline
\end{tabular}

NA = not applicable; NR = not reported.

* When only the mean age per study group (e.g., intervention and control groups) is provided, we present that as a range across groups.

† Employees with the following were excluded: acute illness or injury, self-reported cognitive impairments, psychosis or other severe psychological illness; self-reported chronic conditions (e.g., heart disease or cancer); workers who had a height-adjustable workstation; workers with a body mass index $<25 \mathrm{~kg} / \mathrm{m}^{2}$; and workers who reported sitting $<75 \%$ of a typical workday (32).

‡ Mean age NR; however, study enrolled nurses ages $\geq 49$ y (23).

$\S$ More than half of the 24 worksites in the WellWorks study were described as comprising a majority of blue-collar workers, ranging from $52 \%$ of the workers at the high-volume battery manufacturing worksite to $98 \%$ of workers at the firefighting worksite; the investigators did not describe non-blue-collar workers in detail (18). 


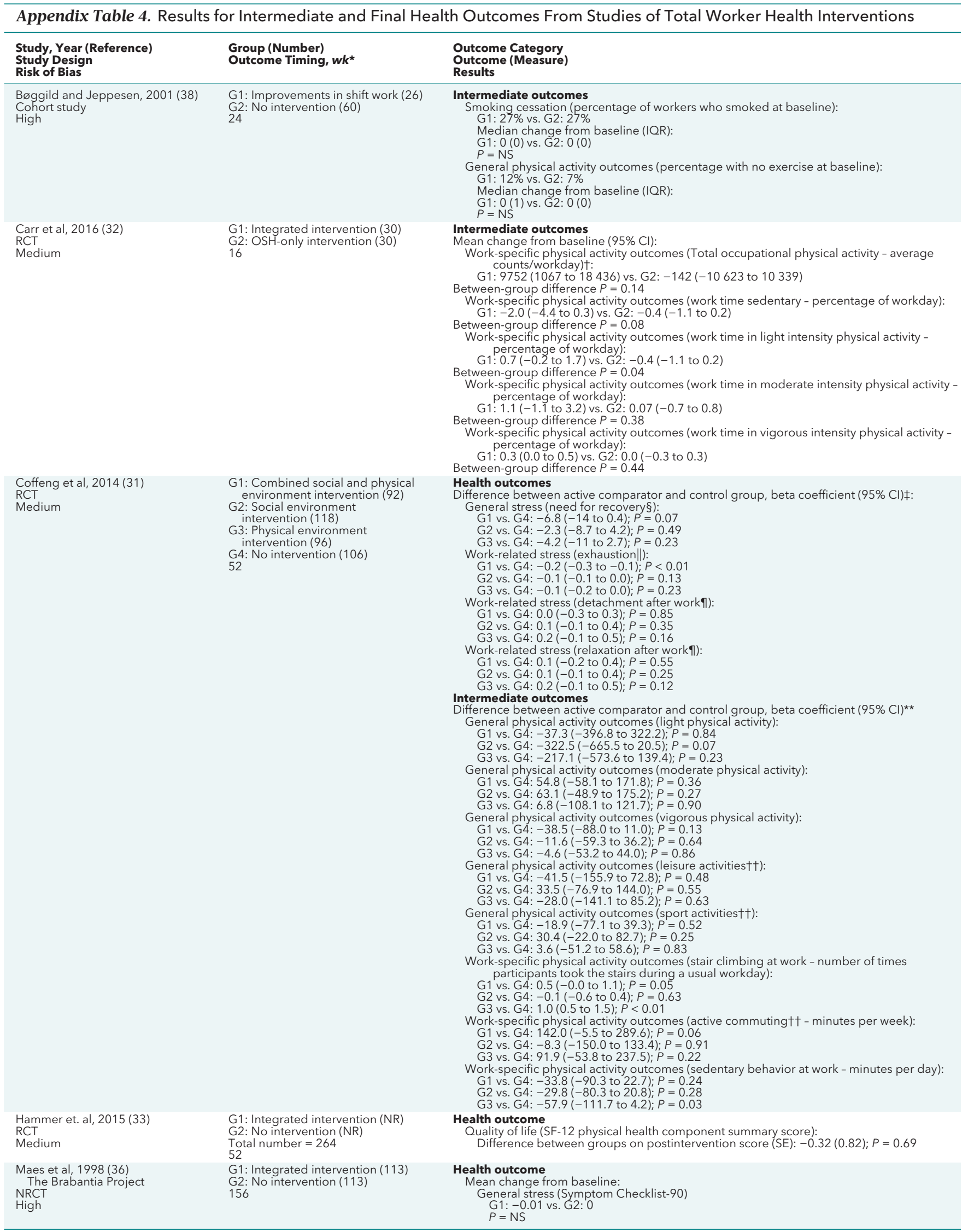




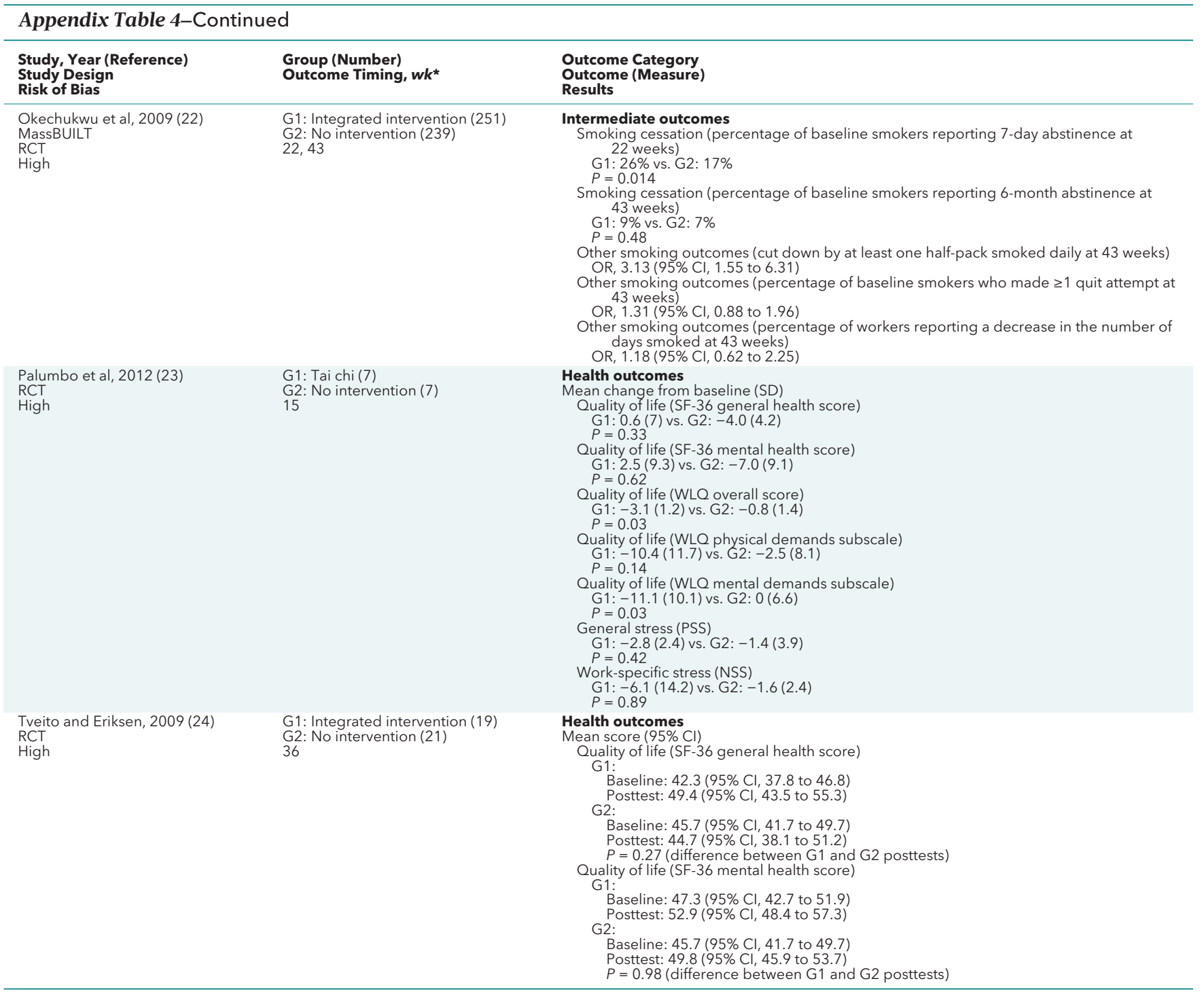

Continued on following page 




Continued on following page 


\begin{tabular}{|c|c|c|}
\hline \multicolumn{3}{|c|}{ Appendix Table 4-Continued } \\
\hline $\begin{array}{l}\text { Study, Year (Reference) } \\
\text { Study Design } \\
\text { Risk of Bias }\end{array}$ & $\begin{array}{l}\text { Group (Number) } \\
\text { Outcome Timing, wk* }\end{array}$ & $\begin{array}{l}\text { Outcome Category } \\
\text { Outcome (Measure) } \\
\text { Results }\end{array}$ \\
\hline $\begin{array}{l}\text { Sorensen et al, } 2005 \text { (26) } \\
\text { Hunt et al, } 2007(27) \\
\text { Barbeau et al, } 2004(28) \\
\text { Healthy Directions-Small Business } \\
\text { Study } \\
\text { RCT } \\
\text { Medium }\end{array}$ & $\begin{array}{l}\text { G1: Integrated intervention (NR) } \\
\text { G2: No intervention (NR) } \\
\text { Overall number }=3092 \S \S \\
78\|\|\end{array}$ & $\begin{array}{l}\text { Intermediate outcomes } \\
\text { Mean change from baseline } \\
\text { Healthy eating behavior (percentage of participants consuming } \geq 5 \text { servings of fruits and } \\
\text { vegetables per day) } \\
\text { Overall sample: } \\
\text { G1: } 5.4 \% \text { vs. G2: } 1.7 \% \\
P=0.41 \\
\text { Subgroup of managers: } \\
\text { G1: }-5.5 \% \text { vs. G2: } 3.6 \% \\
P=0.048 \\
\text { Subgroup of workers: } \\
\text { G1: } 7.5 \% \text { vs. G2: } 1.1 \% \\
P=0.048 \\
\text { Healthy eating behavior (percentage of participants consuming } \leq 3 \text { servings of red meat } \\
\text { per week) } \\
\text { G1: } 4.1 \% \text { vs. G2: } 3.0 \% \\
P=0.72 \\
\text { General physical activity outcomes (percentage of participants who exercise } \geq 2.5 \text { hours } \\
\text { per week) } \\
\text { Overall sample } \\
\text { G1: } 5.4 \% \text { vs. G2: }-0.9 \% \\
P=0.23 \\
\text { Subgroup of managers: } \\
\text { G1: }-2.0 \% \text { vs. G2: } 3.7 \% \\
P=0.09 \\
\text { Subgroup of workers: } \\
\text { G1: } 7.1 \% \text { vs. G2: }-2.1 \% \\
P=0.09\end{array}$ \\
\hline
\end{tabular}

$\mathrm{G}=$ group; HP = health promotion; $\mathrm{IQR}=$ interquartile range; NR = not reported; NRCT = nonrandomized, controlled trial; NS = not significant; NSS = Nursing Stress Scale; OR = odds ratio; OSH = occupational safety and health; PSS = Perceived Stress Scale; RCT = randomized, controlled trial; SF-12 = 12-Item Short Form Health Survey; SF-36 = 36-Item Short Form Health Survey; WLQ = Work Limitations Questionnaire.

* Unless otherwise specified, this is the timing of outcome assessment in relationship to the baseline survey.

† Measured via an ankle-worn accelerometer; this is the sum of all activity counts accumulated on valid accelerometer wear days. Days participants wore the monitor for $<12$ hours were excluded from the analysis (32).

‡ Outcomes are adjusted for age, sex, education, marital status, general health (measured with a single item, "In general, how would you rate your health?" on a scale of 1 [poor] to 5 [excellent] from the Dutch validated version of the SF-36 from the RAND Medical Outcomes Study), job demands, supervisor support, and corresponding baseline measure of the outcome variable. A negative beta indicates a decrease in the outcome measure (31).

$\S$ Assessed using the Need for Recovery after Work scale (score of 0 to 100 with higher scores reflecting greater need). Beta scores used as measures of intervention effect, with negative scores reflecting lower need for recovery compared with no intervention group (31).

|| Measured using the Oldenburg Burnout Inventory (score of 1 to 4 ranging from "totally agree" to "don't agree") (31).

"l Measured using the Recovery Experience Questionnaire (score of 1 to 7 ranging from "never" to "always") (31).

** All outcomes below are adjusted for age, sex, education, marital status, general health (measured with a single item, "In general, how would you rate your health?" on a scale of 1 [poor] to 5 [excellent] from the Dutch validated version of the SF-36 from the RAND Medical Outcomes Study), job demands, supervisor support, and corresponding baseline measure of the outcome variable. A negative beta indicates a decrease in the outcome (31).

†† Physical activity levels were measured using the Short Questionnaire to Assess Health-enhancing Physical Activity Questionnaire. Active commuting refers to walking or cycling to and from work. Leisure activities include walking, cycling, gardening, chores, and sports. Employees were asked to report the frequency (times per week), duration of activities (in minutes), and self-reported intensity (light, moderate, or vigorous) (31).

拉 This was the number of smokers who responded to baseline and follow-up assessments; the study reports that in the cohort of participants who responded to both baseline and follow-up assessments, $23 \%$ were smokers (10).

$\S \S$ Per the authors, 974 workers responded to both the baseline and follow-up survey. This "embedded cohort" is included in the overall analysis, but results are not reported separately for this group (26).

|| $\| 18$ months (26).

\begin{tabular}{|c|c|}
\hline \multicolumn{2}{|c|}{ Appendix Table 5. Definitions of the Grades of Overall Strength of Evidence* } \\
\hline High & $\begin{array}{l}\text { We are very confident that the estimate of effect lies close to the true effect for this outcome } \\
\text { The body of evidence has few or no deficiencies. We believe that the findings are stable } \\
\text { (i.e., another study would not change the conclusions). }\end{array}$ \\
\hline Moderate & $\begin{array}{l}\text { We are moderately confident that the estimate of effect lies close to the true effect for this } \\
\text { outcome. The body of evidence has some deficiencies. We believe that the findings are } \\
\text { likely to be stable, but some doubt remains. }\end{array}$ \\
\hline Insufficient & $\begin{array}{l}\text { We have no evidence, we are unable to estimate an effect, or we have no confidence in the } \\
\text { estimate of effect for this outcome. No evidence is available or the body of evidence has } \\
\text { unacceptable deficiencies, precluding reaching a conclusion. }\end{array}$ \\
\hline
\end{tabular}

* From reference 16. 


\begin{tabular}{|c|c|c|c|c|c|c|c|}
\hline \multicolumn{8}{|c|}{ Appendix Table 6. Strength of Evidence: Smoking Cessation } \\
\hline $\begin{array}{l}\text { Population } \\
\text { Intervention } \\
\text { Comparator } \\
\text { Outcome Measure } \\
\text { Time Point }\end{array}$ & $\begin{array}{l}\text { Studies, } \boldsymbol{n} ; \\
\text { Participants, } n \\
\text { Study Design }\end{array}$ & $\begin{array}{l}\text { Study } \\
\text { Limitations }\end{array}$ & Consistency & Directness & Precision & $\begin{array}{l}\text { Direction and Magnitude of } \\
\text { Effect }\end{array}$ & $\begin{array}{l}\text { Strength of } \\
\text { Evidence }\end{array}$ \\
\hline $\begin{array}{l}\text { Construction laborers (25) } \\
\text { and manufacturing } \\
\text { workers ( } 22 \text { ) } \\
\text { Integrated intervention vs. } \\
\text { no intervention } \\
\text { Self-reported 7-day } \\
\text { abstinence } \\
22-26 \text { weeks }\end{array}$ & $\begin{array}{l}2 ; 737 \\
\text { RCTs }\end{array}$ & $\begin{array}{l}\text { Medium or } \\
\text { High }\end{array}$ & Consistent & Indirect & Precise & $\begin{array}{l}\text { One RCT rated as having medium } \\
\text { ROB (25) found that more } \\
\text { workers in the integrated } \\
\text { intervention group reported } \\
7 \text {-day abstinence at } 26 \text { weeks } \\
\text { than workers in the control } \\
\text { group: } 19 \% \text { vs. } 8 \% ; P=0.03^{*} \\
\text { One RCT rated as having high } \\
\text { ROB (22) found more workers } \\
\text { at intervention worksites } \\
\text { reported 7-day abstinence at } \\
22 \text { weeks compared with } \\
\text { workers at control worksites: } \\
26 \% \text { vs. } 17 \% ; P=0.014\end{array}$ & $\begin{array}{l}\text { Low for } \\
\text { benefit }\end{array}$ \\
\hline
\end{tabular}

$\mathrm{RCT}=$ randomized, controlled trial; $\mathrm{ROB}=$ risk of bias.

* This RCT found also found benefit favoring the integrated intervention for rates of 7 -day abstinence from any tobacco use $(19 \%$ vs. $8 \%$; $P=$ $0.005)(25)$.

\begin{tabular}{|c|c|c|c|c|c|c|c|}
\hline $\begin{array}{l}\text { Manufacturing workers } \\
(10,26) \text { and } \\
\text { construction } \\
\text { workers }(25) \\
\text { Integrated intervention } \\
\text { vs. no intervention } \\
26-104 \text { weeks }\end{array}$ & $\begin{array}{l}3 ; 6056 \\
\text { RCTs }\end{array}$ & $\begin{array}{l}\text { Medium or } \\
\text { High }\end{array}$ & Consistent & Indirect & Precise & $\begin{array}{l}\text { Two RCTs rated as having medium ROB: } \\
\text { One RCT }(n=578)(25) \text { found that } \\
\text { more workers in the intervention } \\
\text { group increased consumption of } \\
\text { fruit and vegetables than workers in } \\
\text { the control group: mean increase in } \\
\text { servings per day, } 1.52(\mathrm{SD}, 3.39) \text { vs. } \\
-0.09(\mathrm{SD}, 3.31) ; P<0.0001 \\
\text { One RCT }(n=3092)(26) \text { found more } \\
\text { workers at intervention worksites } \\
\text { reported consuming } 5 \text { or more } \\
\text { servings of fruits and vegetables per } \\
\text { day than workers at control } \\
\text { worksites*: mean change from } \\
\text { baseline, } 7.5 \% \text { vs. } 1.1 \% ; P=0.048 \\
\text { One RCT }(n=2386) \text { rated as having } \\
\text { high ROB }(10) \text { found more workers } \\
\text { at intervention worksites increased } \\
\text { consumption of fruit and vegetables } \\
\text { than workers at control worksites: } \\
\text { mean change from baseline } \\
\text { servings per day, } 0.22 \text { vs. } 0.09 ; \\
P=0.04\end{array}$ & $\begin{array}{l}\text { Low for } \\
\text { benefit }\end{array}$ \\
\hline
\end{tabular}

$\mathrm{RCT}=$ randomized, controlled trial; $\mathrm{ROB}=$ risk of bias.

* In the overall sample of workers, there was no difference between intervention and control worksites (mean change from baseline percentage consuming $\geq 5$ servings per day: $5.4 \%$ vs. $1.7 \% ; P=0.41$ ), and managers at intervention worksites reported decreased consumption of fruit and vegetables compared with managers at control worksites (mean change from baseline consuming $\geq 5$ servings per day: $-5.5 \%$ vs. $3.6 \%$; $P=$ $0.048)(26)$. 


\begin{tabular}{|c|c|c|c|c|c|c|c|}
\hline $\begin{array}{l}\text { Manufacturing workers (26) } \\
\text { Integrated intervention vs. no } \\
\text { intervention } \\
78 \text { weeks }\end{array}$ & $\begin{array}{l}1 ; 3092 \\
\text { RCT }\end{array}$ & Medium & Unknown & Indirect & Imprecise & $\begin{array}{l}\text { Percentage of workers } \\
\text { who reported } \\
\text { consuming } \leq 3 \text { servings } \\
\text { of red meat per week: } \\
\text { mean change from } \\
\text { baseline, } 4.1 \% \text { in the } \\
\text { intervention group vs. } \\
3.0 \% \text { in the control } \\
\text { group; } P=0.72\end{array}$ & Insufficient \\
\hline
\end{tabular}

$\mathrm{RCT}=$ randomized controlled trial. 


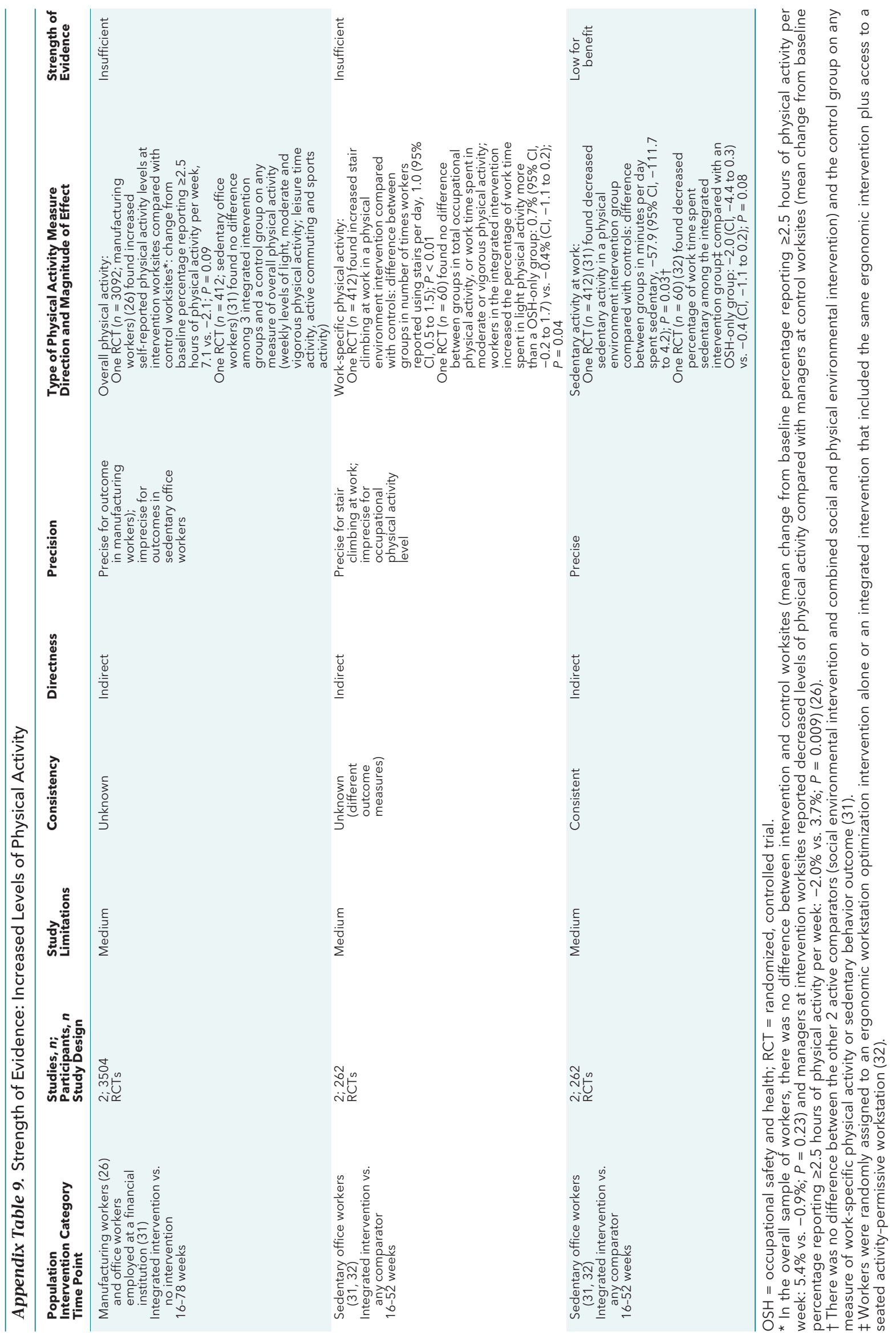




\begin{tabular}{|c|c|c|c|c|c|c|c|}
\hline \multicolumn{8}{|c|}{ Appendix Table 10. Strength of Evidence: Work Stress } \\
\hline $\begin{array}{l}\text { Population } \\
\text { Intervention Category } \\
\text { Time Point }\end{array}$ & $\begin{array}{l}\text { Studies, } n ; \\
\text { Participants, } n \\
\text { Study Design }\end{array}$ & $\begin{array}{l}\text { Study } \\
\text { Limitations }\end{array}$ & Consistency & Directness & Precision & Direction and Magnitude of Effect & $\begin{array}{l}\text { Strength of } \\
\text { Evidence }\end{array}$ \\
\hline $\begin{array}{l}\text { Office workers employed } \\
\text { at a financial } \\
\text { institution ( } 31) \\
\text { Integrated intervention } \\
\text { vs. no intervention } \\
52 \text { weeks }\end{array}$ & $\begin{array}{l}1 ; 412 \\
\mathrm{RCT}\end{array}$ & Medium & Unknown & Direct & Imprecise & $\begin{array}{l}\text { Workers in the combined intervention } \\
\text { group* experienced greater } \\
\text { reduction in exhaustion measured } \\
\text { by the Oldenburg Burnout Inventory } \\
\text { than the control group. There was } \\
\text { no difference between the control } \\
\text { group and any of the } 3 \text { active } \\
\text { comparator arms on the following } \\
\text { outcomes: need for recovery after } \\
\text { work, detachment after work, and } \\
\text { relaxation after work. }\end{array}$ & Insufficient \\
\hline
\end{tabular}

$\mathrm{RCT}=$ randomized, controlled trial.

* The study randomly assigned workers to 1 of 4 groups: 1) no intervention control group, 2) social environment intervention, 3) physical environment intervention, and 4) combined social and physical environment intervention.

\begin{tabular}{|c|c|c|c|c|c|c|c|}
\hline \multicolumn{8}{|c|}{ Appendix Table 11. Strength of Evidence: Quality of Life (SF-12) } \\
\hline $\begin{array}{l}\text { Construction and utility } \\
\text { workers ( } 33 \text { ) } \\
\text { Integrated intervention } \\
\text { vs. no intervention } \\
52 \text { weeks }\end{array}$ & $\begin{array}{l}1 ; 264 \\
\text { RCT }\end{array}$ & Medium & Unknown & Direct & Imprecise & $\begin{array}{l}\text { No difference between groups* } \\
\text { on the SF-12 physical health } \\
\text { component summary score: } \\
\text { difference between groups } \\
\text { on postintervention score } \\
\text { (SE): }-0.32(0.82) ; P=0.69\end{array}$ & Insufficient \\
\hline
\end{tabular}

$\mathrm{RCT}=$ randomized, controlled trial; SF-12 $=12$-Item Short Form Health Survey.

* Workers were randomly assigned to an intervention aimed at improving work-life stress (via supervisor behavior training and employee work groups) or no intervention.

\begin{tabular}{|c|c|c|c|c|c|c|c|}
\hline $\begin{array}{l}\text { Construction and utility } \\
\text { workers ( } 33 \text { ) } \\
\text { Integrated intervention } \\
\text { vs. no intervention } \\
52 \text { weeks }\end{array}$ & $\begin{array}{l}1 ; 264 \\
\mathrm{RCT}\end{array}$ & Medium & Unknown & Direct & Imprecise & $\begin{array}{l}\text { No difference between groups* } \\
\text { in mean safety participation } \\
\text { scores }(0.14 ; \mathrm{SE}, 0.09 ; \\
P=0.014) \text { or mean safety } \\
\text { compliance scores }(-0.02 ; \\
\mathrm{SE}, 0.08 ; P=0.83) \text {. }\end{array}$ & Insufficient \\
\hline
\end{tabular}

$\mathrm{RCT}=$ randomized, controlled trial.

* Workers were randomly assigned to an intervention aimed at improving work-life stress (via supervisor behavior training and employee work groups) or no intervention. Safety compliance and safety participation were measured via self-report on items such as "I use the correct safety procedures" and "I voluntarily carry out tasks or activities that help to improve workplace safety"; responses were rated on a 5-point scale and computed as a mean response (higher scores $=$ higher levels of safety and compliance). 


\begin{tabular}{|c|c|c|c|c|c|c|c|}
\hline $\begin{array}{l}\text { Population } \\
\text { Intervention Category } \\
\text { Time Point }\end{array}$ & $\begin{array}{l}\text { Studies, } n \text {; } \\
\text { Participants, } n \\
\text { Study Design }\end{array}$ & $\begin{array}{l}\text { Study } \\
\text { Limitations }\end{array}$ & Consistency & Directness & Precision & $\begin{array}{l}\text { Direction and Magnitude of } \\
\text { Effect }\end{array}$ & $\begin{array}{l}\text { Strength of } \\
\text { Evidence }\end{array}$ \\
\hline $\begin{array}{l}\text { Sedentary desk job } \\
\text { workers ( } 32 \text { ); } \\
\text { construction and } \\
\text { utility workers ( } 33) \\
\text { Integrated intervention } \\
\text { vs. any comparator } \\
16 \text { to } 52 \text { weeks }\end{array}$ & $\begin{array}{l}2 ; 324 \\
\mathrm{RCT}\end{array}$ & Medium & Unknown & Indirect & Imprecise & $\begin{array}{l}\text { One RCT ( } n=264 \text {; construction } \\
\text { and utility workers) found a } \\
\text { small statistically significant } \\
\text { improvement in MAP in the } \\
\text { integrated intervention } \\
\text { group* compared with } \\
\text { controls at } 52 \text { weeks (change } \\
\text { in MAP, }-2.15 \mathrm{~mm} \mathrm{Hg} ; \\
\mathrm{SE}, 1.03 ; P=0.038)(33) \\
\text { One RCT ( } n=60 \text {; sedentary } \\
\text { office workers) found no } \\
\text { difference between groups } \\
\text { at } 16 \text { weeks; only } P \text { values } \\
\text { reported for systolic blood } \\
\text { pressure }(P=0.90 \text { ) and } \\
\text { diastolic blood pressure } \\
(P=0.48)(32)\end{array}$ & Insufficient \\
\hline
\end{tabular}

MAP = mean arterial blood pressure; RCT $=$ randomized, controlled trial.

* Workers were randomly assigned to an intervention aimed at improving work-life stress (via supervisor behavior training and employee work groups) or no intervention.

† Workers were randomly assigned to an ergonomic workstation optimization intervention alone or an integrated intervention that included the same ergonomic intervention plus access to a seated activity-permissive workstation (32).

\begin{tabular}{|c|c|c|c|c|c|c|c|}
\hline \multicolumn{8}{|c|}{ Appendix Table 14. Strength of Evidence: Weight } \\
\hline $\begin{array}{l}\text { Sedentary desk job } \\
\text { workers ( } 32 \text { ) } \\
\text { Integrated intervention vs. } \\
\text { OSH-only intervention } \\
16 \text { weeks }\end{array}$ & $\begin{array}{l}1 ; 60 \\
\text { RCT }\end{array}$ & Medium & Unknown & Indirect & Imprecise & $\begin{array}{l}\text { No difference between } \\
\text { groups }{ }^{*} \text { in the weight } \\
\text { change from baseline } \\
\text { to follow-up at } 16 \\
\text { weeks }(P=0.80 \text {; data } \\
\text { not reported) }\end{array}$ & Insufficient \\
\hline
\end{tabular}

$\mathrm{OSH}=$ occupational safety and health; RCT = randomized, controlled trial.

* Workers were randomly assigned to an ergonomic workstation optimization intervention alone or an integrated intervention that included the same ergonomic intervention plus access to a seated activity-permissive workstation (32). 